\title{
Role of RF power on physical properties of RF magnetron sputtered GaN/p-Si(1 0 0) thin film
}

\author{
Asim Mantarci ${ }^{1, *}$, Mutlu KundaKÇI ${ }^{2}$ \\ ${ }^{1}$ Department of Physics, Faculty of Art and Science, Muş Alparslan University, Muş, 49250, Turkey \\ ${ }^{2}$ Department of Physics, Faculty of Science, Atatürk University, Erzurum, 25250, Turkey
}

\begin{abstract}
GaN thin films were deposited on p-Si(l $\left.\begin{array}{lll}1 & 0\end{array}\right)$ substrates using RF magnetron sputtering at various RF powers. Influence of RF power on morphological, optical and structural properties of $\mathrm{GaN}$ thin films were investigated and presented in detail. XRD results proved that the films were polycrystalline in structure with $\left(\begin{array}{lll}1 & 0 & 0\end{array}\right)$ and $\left(\begin{array}{lll}1 & 1 & 0\end{array}\right)$ planes of hexagonal GaN. It was found that increasing RF power led to deterioration of crystal structure of the films due to increased decomposition of GaN. Stress in $\mathrm{GaN}$ thin films was calculated from XRD measurements and the reasons for this stress were discussed. Furthermore, it was analyzed and interpreted whether the experimental measurement results support each other. $\mathrm{E}_{2}$ (high) optical phonon mode of hexagonal GaN was obtained from the analysis of Raman results. UV-Vis spectroscopy results showed that optical band gap of the films varied by changing RF power. The reasons of this variation were discussed. AFM study of the surfaces of the GaN thin films showed that some of them were grown in Stranski-Krastanov mode and others were grown in Frank-Van der Merwe mode. AFM measurements revealed almost homogeneous, nanostructured, low-roughness surface of the GaN thin films. SEM analysis evidenced agglomerations in some regions of surface of the films and their possible causes have been discussed. It has been inferred that morphological, optical, structural properties of GaN thin film can be changed by controlling RF power, making them a potential candidate for LED, solar cell, diode applications.
\end{abstract}

Keywords: RF magnetron sputtering; thin film, III-nitride; GaN; semiconductor

\section{Introduction}

III-nitride semiconductors (direct-wide band gap of $0.65 \mathrm{eV}$ to $6.2 \mathrm{eV}$ ) have become key materials in high temperature electronics and optoelectronics to improve device technology [1, 2]. The class of these materials has been deeply investigated by several distinguished researchers to analyze them and to apply in high technology devices [3-11]. GaN material belongs to III-nitrides group, having a direct wide band gap $(\sim 3.4 \mathrm{eV})$, high electron mobility [12], and high breakdown voltage [13], high melting point [14], good mechanical hardness and thermal stability. It can be the basis for many significant device applications such as high-power transistors $[15,16]$, solar cells [17, 18], photodetectors [19], light emitting diodes (LED) [20-22] and optical devices with short wavelength [23]. Gallium nitride generally

*E-mail: asimmantarci@gmail.com crystallizes in two phases, as a hexagonal structure and a cubic structure. Among these, hexagonal structure of $\mathrm{GaN}$ is the most stable; therefore, it is used as a basis for production of some optoelectronic devices, such as light-emitting diodes however, the hexagonal GaN exhibits piezoelectricinduced and spontaneous polarization being a disadvantage for devices. Cubic GaN shows more isotropic physical properties without this kind of polarization influence [24]. Many techniques can be used to grow GaN thin films, such as molecular beam epitaxy (MBE) [25], atomic layer deposition [26], sputtering [27], metal-organic chemical vapor deposition (MOCVD) [28], thermionic vacuum arc (TVA) [29, 30], sol-gel [31], pulsed laser deposition (PLD) [32]. By RF sputtering method, high quality $\mathrm{GaN}$ thin film can be grown at lower temperature Several studies can be found in the literature [33] related to this technique. Shinoda et al. [34] reported that $\mathrm{GaN}$ has been deposited on $\mathrm{Al}_{2} \mathrm{O}_{3}$ substrates by sputtering. Increasing 
substrate temperature resulted in quality improvement of the crystalline film. Surface morphology of the material at Ga rich condition has been found to be smooth and RMS roughness value has been determined to be $1.0 \mathrm{~nm}$. Li et al. [35] used RF magnetron sputtering for producing $\mathrm{p}-\mathrm{CuS} / \mathrm{n}-\mathrm{GaN}$ heterojunction. It was found that quality of the films can be improved by controlling annealing temperature. Diode parameters showed good rectifying properties and low leakage. Turn-on voltage of the diode was $1.2 \mathrm{~V}$. It was evidenced that optical band gap energies of the material were altered by annealing temperature. Abud et al. [36] studied GaN films deposited on a flat and porous silicon substrate by RF sputtering method. The XRD results confirmed hexagonal structure of the sputtered GaN. Photoluminescence spectroscopy was used to obtain optical parameters of the films, confirming good optical behavior of the material. In another study, Eu-doped GaN (GaN:Eu) films were successfully grown on $\mathrm{c}-\mathrm{Al}_{2} \mathrm{O}_{3}, \mathrm{Si}\left(\begin{array}{lll}1 & 0 & 0\end{array}\right)$ and $\mathrm{GaAs}\left(\begin{array}{lll}1 & 0 & 0\end{array}\right)$ substrates by RF magnetron sputtering method. It was found that lattice constants of the material were decreased with annealing temperature [37]. Liuan et al. [38] researched growth of TiN/AlO/GaN MOS structure by RF reactive sputtering and showed its excellent dielectric behavior. Shinoda et al. [39] reported on $\mathrm{GaN}$ and alloys such as $\mathrm{InGaN}$ and $\mathrm{AlGaN}$ deposited on $\mathrm{Al}_{2} \mathrm{O}_{3}$ substrate using $\mathrm{RF}$ magnetron sputtering method. Structures of the materials were investigated for Ga-rich and nitrogen-rich conditions. It has been stated that Ga-rich grown material shows flat surface and nitrogen-rich grown material shows pyramid type structure. Kuo et al. [40] studied the effect of $\mathrm{Mg}$ doping on physical properties of thin film produced by RF sputtering method. They achieved environmental friendly P-N diodes. In other study, GaN thin films were grown by reactive RF sputtering of GaAs target. Optical parameters of $\mathrm{GaN}$ thin films were studied by spectroscopic ellipsometry [41].

When we performed the studies in the literature, it was not found any study about the impact of RF power on physical properties of $\mathrm{GaN} / \mathrm{p}-\mathrm{Si}$ thin films obtained by RF magnetron sputtering. Therefore, we think that the study of this subject may be important in terms of satisfying scientific curiosity and giving some contribution to the literature. In this study, RF power dependency of physical properties of GaN/p-Si thin films obtained using RF magnetron sputtering was researched. Two aspects of our work can be considered as a novelty. In spite of great number of studies on the growth of $\mathrm{GaN}$ thin films found in the literature, as we mentioned above, the effect of changing RF power on GaN/p-Si thin film growth has not been studied. The other factor is the RF sputtering technique, which we used to grow GaN thin films. This technique is cheaper than other known techniques (e.g. molecular beam epitaxy) and enabled us to produce thin films in a shorter time. These advantages of the growth technique are important for industry and researchers.

XRD measurements were used to analyze structure of thin films. Raman spectra were used to analyze phonon modes of the material. The optical measurements have been used to determine optical band gap values of the materials. Surface morphology of the films was examined with scanning electron microscopy (SEM) and atomic force microscopy (AFM). This research aimed to study the effect of RF power on physical properties of $\mathrm{GaN} / \mathrm{p}$-Si thin film, as well as to provide information on optical, morphological, and structural properties of the grown material.

\section{Experimental}

Sputtering method is a plasma-based deposition process in which energetic ions move towards the target. The working mechanism of this method is basically as follows: ions hit the target and atoms are sputtered from the surface of the target. These atoms move towards the surface of the substrate, and thin film is formed here by condensation. For a conductive material, DC sputtering method can be used, however, for nonconductive materials RF sputtering is appropriate. RF magnetron sputtering has the advantage that magnets better ionize the material in the electric and magnetic field and allow the material to transform into plasma form. RF magnetron sputtering with PVD-Midas 3M model (System number: VK-1601-2) was used to produce GaN thin films at DAYTAM (Center 
of East Anatolian High-Technology Research and Application). The system, provided with fully automated control, has the following technical parameters: maximum temperature of substrate heating - $800{ }^{\circ} \mathrm{C}$, substrate diameter $-10 \mathrm{~cm}$ to $20 \mathrm{~cm}$, substrate rotation - $3 \mathrm{rpm}$ to $30 \mathrm{rpm}$; final vacuum pressure $\leqslant 6.65 \times 10^{-6} \mathrm{~Pa}$. To eliminate any defects (oxygen, etc.), it was equipped with a turbomolecular and a mechanical pump. The GaN target with purity $99.99 \%(4 \mathrm{~N})$ and with $5 \mathrm{~cm}$ diameter and $0.33 \mathrm{~cm}$ thickness was purchased from ACI Alloys, Inc., with lot No. 22709-16-02. p-Si(1 $\left.\begin{array}{lll}1 & 0\end{array}\right)$ was bought from Sigma-Aldrich Chemistry Company. Before growing thin films, RCA-1 (Radio Corporation of America-1) and RCA-2 (Radio Corporation of America-2) cleaning procedure [42] were applied to remove possible contaminations. All of substrates were cut with a diamond cutter at the desired size. ISO 7 class cleaning room was used in all experimental processes. $3 \mathrm{sccm}$ nitrogen gas and $75 \mathrm{sccm}$ argon gas were applied to the system as sputtering gases. $50 \mathrm{~W}, 75 \mathrm{~W}, 100 \mathrm{~W}, 125 \mathrm{~W}$ RF power was employed to evaluate RF power effect on the growth of $\mathrm{GaN}$. Growth conditions of our material under different radio frequency power are presented in Table 1. We measured $\mathrm{GaN}$ thin film thicknesses with a surface profiler P7 (KLA-tensor). In addition, the thicknesses were measured by the RF magnetron sputtering sensor. Calibration of the RF magnetron sputtering sensor has been performed by comparing these values with the profilometer data. For physical characterization of produced $\mathrm{GaN}$ thin films, field emission scanning electron microscopy (FE-SEM), atomic force microscopy (AFM), UVVis-NIR spectrophotometry, micro Raman spectroscopy, and X-ray diffraction (XRD) were employed. Optical analysis of the films was performed with the help of UV-Vis-NIR spectrophotometer model LAMBDA. Field emission scanning electron microscope (FE-SEM) model 300, by Zeiss Sigma, was used for morphological and surface analysis of the materials. PANalytical X-ray diffraction system $(\mathrm{CuK} \alpha=1.5406 \AA)$ with Empyrean model has been used to analyze the structure of $\mathrm{GaN}$ thin films. Morphological analysis of $\mathrm{GaN}$ thin films was carried out by AFM-500II. Micro Raman spectra obtained with a spectrometer model Alpha $300 \mathrm{R}$ were used for optical phonon mode analysis. All measurements were taken at advanced spectroscopy laboratories at DAYTAM (Center of East-Anatolian High-Technology Research, Application).

\section{Results and discussion}

\subsection{Structural analysis}

XRD spectra of GaN/p-Si films obtained at various RF powers are presented in Fig. 1. 32.61 ${ }^{\circ}$, $32.60^{\circ}, 32.60^{\circ}, 32.60^{\circ}$ peaks have been detected under $50 \mathrm{~W}, 75 \mathrm{~W}, 100 \mathrm{~W}, 125 \mathrm{~W}$ RF power growth conditions. They stem from diffraction of $\left(\begin{array}{lll}1 & 0 & 0\end{array}\right)$ plane of hexagonal GaN with PDF Code: 01-0760703 from Inorganic Crystal Structure Database (ICSD) [43]. In addition, $61.39^{\circ}, 61.37^{\circ}, 61.37^{\circ}$, $61.37^{\circ}$ peaks are observed. These peaks have originated from (1 110$)$ plane of hexagonal GaN (PDF code: 01-079-2499 from Inorganic Crystal Structure Database (ICSD)) [44]. Results of XRD measurements have proved that the $\mathrm{GaN}$ thin films have polycrystalline structure. It is seen that the peak of $\sim 32.38^{\circ}$ was shifted to $\sim 32.6^{\circ}$ for $\left(\begin{array}{lll}1 & 0 & 0\end{array}\right)$ plane of hexagonal $\mathrm{GaN}$ and the peak of $59.70^{\circ}$ was shifted to $61.37^{\circ}$ for $\left(\begin{array}{lll}1 & 1 & 0\end{array}\right)$ planes of hexagonal GaN. It is inferred that these shifts originate from impurities and defects occurred in the film during the growth. We have also detected an intense peak at $\sim 69^{\circ}$ belonging to $\mathrm{p}-\mathrm{Si}\left(\begin{array}{lll}1 & 0 & 0\end{array}\right)$. It is in agreement with literature study [45]. Grain sizes of GaN thin films have been calculated by Scherrer relation [46]:

$$
D=\frac{K \lambda}{\beta \cos \theta}
$$

$\mathrm{K}=0.9$ is a constant, $\lambda$ is the $\mathrm{X}$-ray wavelength, $\beta$ is full width at half maximum intensity, $\theta$ is Bragg diffraction angle. The average grain size (D) of our films was calculated from the highest peak intensity. Structural parameters of $\mathrm{GaN} / \mathrm{p}-\mathrm{Si}$ thin films grown by RF magnetron sputtering at different RF powers have been shown in Table 2. By increasing RF power from $50 \mathrm{~W}$ to $125 \mathrm{~W}$, FWHM value has increased and grain size of the thin film has decreased. This is caused by deterioration in crystal structure of the GaN thin film caused by high 
Table 1. Growth parameters of GaN/p-Si thin films at different RF powers.

\begin{tabular}{cccccc}
\hline $\begin{array}{c}\text { RF } \\
\text { power }[\mathrm{W}]\end{array}$ & $\begin{array}{c}\text { Substrate } \\
\text { temperature }\left[{ }^{\circ} \mathrm{C}\right]\end{array}$ & $\begin{array}{c}\text { Base } \\
\text { pressure }[\mathrm{Pa}]\end{array}$ & $\begin{array}{c}\text { Working } \\
\text { pressure }[\mathrm{Pa}]\end{array}$ & $\begin{array}{c}\text { Film } \\
\text { thickness [nm] }\end{array}$ & $\begin{array}{c}\text { Growth } \\
\text { rate }[\AA / \mathrm{A}]\end{array}$ \\
\hline \hline 50 & 300 & $2 \times 10^{-4}$ & $8.91 \times 10^{-3}$ & 100 & 0.1 \\
75 & 300 & $1.86 \times 10^{-4}$ & $8.71 \times 10^{-3}$ & 100 & 0.2 \\
100 & 300 & $8.91 \times 10^{-5}$ & $8.5 \times 10^{-3}$ & 100 & 0.3 \\
125 & 300 & $2.39 \times 10^{-4}$ & $8.5 \times 10^{-3}$ & 100 & 0.4 \\
\hline
\end{tabular}

RF power which led to increased decomposition of GaN (increment in vacancies of gallium and nitrogen), and resulted in deterioration of the crystal quality [47].

$\mathrm{GaN} / \mathrm{p}$-Si thin film structures with the best and the worst crystallinity have been obtained for $50 \mathrm{~W}$ $\mathrm{RF}$ and $125 \mathrm{~W}$ RF power, respectively. With formula 2 (Bragg relation [48]) and formula 3, lattice parameters $\mathrm{c}$ and a have been computed:

$$
\begin{gathered}
d_{h k l}=\frac{\lambda}{\left(2 \sin \theta_{h k l}\right)} \\
\frac{1}{d_{h k l}}=\sqrt{\frac{4}{3}\left(\frac{h^{2}+h \cdot k+k^{2}}{a^{2}}\right)+\frac{l^{2}}{c^{2}}}
\end{gathered}
$$

$\mathrm{d}$ is interplanar spacing, $\lambda$ is the wavelength of $\mathrm{X}$-ray source, $\mathrm{h} \mathrm{k} 1$ stand for Miller indices, $\theta_{\mathrm{h} \mathrm{k} 1}$ is reflection angle from $\mathrm{h} \mathrm{k} 1$ plane, $\mathrm{a}$ and $\mathrm{c}$ are the lattice parameters for hexagonal material. Lattice parameters of the studied GaN films are given in Table 2. Strain in GaN thin film for a and c lattice parameters can be calculated by formula 4 [49]:

$$
\varepsilon_{c}=\frac{c-c_{0}}{c_{0}} \quad, \quad \varepsilon_{a}=\frac{a-a_{0}}{a_{0}}
$$

where $\varepsilon_{\mathrm{c}}$ and $\varepsilon_{\mathrm{a}}$ represent strain in $\mathrm{GaN}$ thin film for $\mathrm{c}$ and a lattice parameters, respectively; $\mathrm{c}_{0}$ and $\mathrm{a}_{0}$ are lattice parameters of $\mathrm{GaN}$ stress-free film $\left(\mathrm{c}_{0}=0.5185 \mathrm{~nm}, \mathrm{a}_{0}=0.3188 \mathrm{~nm}[50]\right)$. The strain in the lattice parameter $\mathrm{c}$ of $\mathrm{GaN}$ thin film for ( 100 l 0 ) plane has been found to be -0.0022 , while the strain in the lattice parameter a of $\mathrm{GaN}$ thin film for $\left(\begin{array}{lll}1 & 0 & 0\end{array}\right)$ plane has been found to be -0.0062 for all the films sputtered at different RF powers. In contrast, the strain in the lattice parameter $\mathrm{c}$ of $\mathrm{GaN}$ thin film for $\left(\begin{array}{lll}1 & 1 & 0\end{array}\right)$ plane has been found to be -0.0495 for $50 \mathrm{~W}$ RF power and -0.0492 for $75 \mathrm{~W}, 100 \mathrm{~W}, 125 \mathrm{~W}$. It was also stated that the strain in the lattice parameter a of the GaN thin film for (1 110 ) plane was -0.0533 for $50 \mathrm{~W}$ RF power and -0.0530 for $75 \mathrm{~W}, 100 \mathrm{~W}, 125 \mathrm{~W}$, as shown in Table 3 . The minus sign shows that the lattice parameter values are decreasing, which means compressive stress. In-plane stress $\sigma_{\mathrm{a}}$ of $\mathrm{GaN}$ thin film can be obtained from formula 5 and formula 6 [51]:

$$
\begin{gathered}
\frac{\varepsilon_{c}}{\varepsilon_{a}}=-\frac{2 v}{(1-v)} \\
\varepsilon_{c}=-E^{-1} \sigma_{a} 2 v
\end{gathered}
$$

$\varepsilon_{\mathrm{c}}$ and $\varepsilon_{\mathrm{a}}$ represent the strain in GaN thin film for $\mathrm{c}$ and a lattice parameters, $v$ is Poisson ratio, E (196 GPa) is Young modulus of GaN [52]. We obtained the in-plane stress $\sigma_{a}$ of $\left(\begin{array}{lll}1 & 0 & 0\end{array}\right)$ oriented $\mathrm{GaN}$ thin film deposited at $50 \mathrm{~W}$ RF power as $0.9996 \mathrm{GPa}$. Other in-plane stress values have been given in Table 3 . These stress values in GaN thin films were supported by and compatible with the Raman results which are presented in the analysis section. We can make the following evaluations when we analyze the causes of this stress in $\mathrm{GaN}$ thin film. The p-Si used has a cubic structure with $\left(\begin{array}{lll}1 & 0 & 0\end{array}\right)$ orientation and its lattice constant is $\mathrm{a}=5.4037 \AA$. Lattice parameters of GaN thin films obtained from XRD results are smaller than the lattice parameters of the substrate. Since the GaN thin film has a smaller lattice constant relative to the substrate as it grows, it will compress the substrate lattice parameter to its size. This will cause compressive stress to occur. Another factor that allows compressive stress to occur in $\mathrm{GaN}$ thin films is the difference between thermal expansion coefficients. Thermal expansion coefficients of gallium nitride and $\mathrm{p}-\mathrm{Si}$ are 
$\alpha_{\mathrm{GaN}}=5.6 \times 10^{-6} \mathrm{~K}^{-1}, \alpha_{\mathrm{p}-\mathrm{Si}}=\sim 2.6 \times 10^{-6} \mathrm{~K}^{-1}$, respectively. As the films are growing at $300{ }^{\circ} \mathrm{C}$ substrate temperature they are expanding in the ratio of thermal expansion coefficients since thermal coefficients of the substrate and the film are different. When the films are cooled down, compressive stress is generated in the thin films. From this reasoning it can be inferred that residual stress in GaN thin films comes from two factors: internal stress (lattice parameters difference) and thermal stress (thermal coefficient difference). Besides these factors, another reason of strain in GaN thin film may be attributed to point defects (coming from surface plasma interaction) and oxygen impurities (always in the system) in GaN thin film, also mentioned in the literature [53]. Analysis of XRD results for GaN thin films is extremely important in terms of device applications, because we can get from it important information about crystal quality. Optimization of growth conditions aims to produce good crystals of $\mathrm{GaN} / \mathrm{p}-\mathrm{Si}\left(\begin{array}{lll}1 & 0 & 0\end{array}\right)$. By appropriate choice of RF power values, we were able to improve the crystal structure to some extent. But in the future, more detailed study of RF power effects on structure of $\mathrm{GaN}$ thin film would be necessary to optimize the growth conditions in order to obtain high quality GaN thin films. Although our system has been vacuumed to a sufficient level, reducing the impurities in the system could provide us with better quality $\mathrm{GaN}$ thin films. Results from XRD measurement confirm that RF power plays an important role in controlling structural properties of $\mathrm{GaN} / \mathrm{p}-\mathrm{Si}\left(\begin{array}{lll}1 & 0 & 0\end{array}\right)$ structures.

\subsection{Morphological analysis by AFM}

Fig. 2 shows AFM images of $\mathrm{GaN} / \mathrm{p}-\mathrm{Si}$ thin films obtained at various RF power growth conditions. From the AFM measurements, the maximum height of GaN/p-Si(l $\left.\begin{array}{lll}1 & 0\end{array}\right)$ was measured as $4.60 \mathrm{~nm}$ for the film sputtered at $75 \mathrm{~W}$ RF power. The minimum height of GaN/p-Si has been measured to be 2.63 for the film sputtered at $100 \mathrm{~W} \mathrm{RF}$ power. We obtained the highest average absolute slope $(\Delta \mathrm{a})$ to be $6.37^{\circ}$ for $75 \mathrm{~W}$ RF power growth condition. The lowest average absolute slope is $4.46^{\circ}$ for $125 \mathrm{~W}$ RF power. Maximum depth $\mathrm{R}_{\mathrm{V}}$

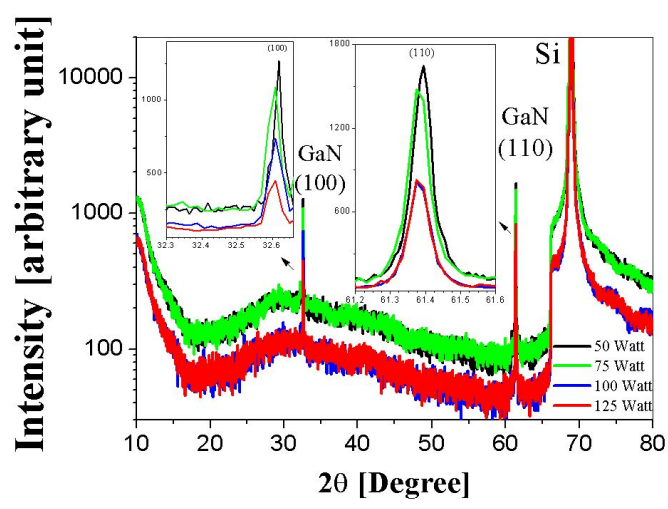

Fig. 1. XRD spectra of GaN/p-Si thin films obtained at various RF powers.

of $\mathrm{GaN} / \mathrm{p}-\mathrm{Si}$ thin film has been $1.87 \mathrm{~nm}$ for $125 \mathrm{~W}$ RF power. Maximum depth $\mathrm{R}_{\mathrm{V}}$ of $\mathrm{GaN} / \mathrm{p}-\mathrm{Si}$ thin film has been $3.10 \mathrm{~nm}$ for $75 \mathrm{~W}$ RF power. The highest root mean square (RMS) roughness was measured to be $1.35 \mathrm{~nm}$ for $75 \mathrm{~W}$ RF power, whereas the lowest root mean square (RMS) roughness was measured to be $0.74 \mathrm{~nm}$ for $125 \mathrm{~W}$ RF, as shown in Fig. 3. Morphological parameters of GaN/p-Si thin films for different RF powers have been shown in Table 4. Analysis of the results of AFM measurements, allows following interpretation. Increasing RF power from $50 \mathrm{~W}$ to $75 \mathrm{~W}$ results in rougher surface by $0.26 \mathrm{~nm}$, indicating that the film has grown in Stranski-Krastanov mode (layer plus island growth mode). Increasing RF power from $75 \mathrm{~W}$ to $100 \mathrm{~W}$ leads to smoother surface by $0.31 \mathrm{~nm}$, implying that the film has grown in Frank-Van der Merwe mode (layer by layer growth mode). Increasing RF power from $100 \mathrm{~W}$ to $125 \mathrm{~W}$ results in smoother surface by $0.15 \mathrm{~nm}$, suggesting that the $\mathrm{GaN}$ thin film has grown in Frank-Van der Merwe mode (layer by layer growth mode). Other factors that can affect surface roughness of GaN thin film can be Ehrlich-Schwöbel energy barrier at the step-edges making surface features such as hillocks step meandering, presented in the literature [54]. It is thought that some little bumps in XRD pattern may correspond to textured sample. AFM results have shown almost homogeneous, nanostructured, low-roughness surface of the $\mathrm{GaN}$ thin films. Average roughness of $\mathrm{GaN}$ thin films has ranged from $0.7 \mathrm{~nm}$ to $20 \mathrm{~nm}$ 
Table 2. Structural parameters of GaN/p-Si thin films grown by RF magnetron sputtering at for different RF powers.

\begin{tabular}{|c|c|c|c|c|c|c|c|c|c|}
\hline $\begin{array}{c}\mathrm{RF} \\
\text { power [W] }\end{array}$ & $(\mathrm{h} \mathrm{k} \mathrm{l)}$ & $\begin{array}{c}\text { FWHM } \\
{\left[{ }^{\circ}\right]} \\
\end{array}$ & $\begin{array}{c}2 \theta \\
\text { (observed) }\left[{ }^{\circ}\right] \\
\end{array}$ & $\begin{array}{c}2 \theta(*) \\
{\left[{ }^{\circ}\right]} \\
\end{array}$ & $\begin{array}{c}\text { d-values } \\
{[\AA \AA]} \\
\end{array}$ & $\begin{array}{c}\text { d-values }(*) \\
[\AA]] \\
\end{array}$ & $\begin{array}{c}\text { Lattice } \\
\text { parameters }(*)[\AA]\end{array}$ & $\begin{array}{c}\text { Lattice } \\
\text { parameters }[\AA]]\end{array}$ & $\begin{array}{c}\text { Grain } \\
\text { size D }[\mathrm{nm}] \\
\end{array}$ \\
\hline \multirow[t]{2}{*}{50} & $\left(\begin{array}{lllllll}1 & 0 & 0\end{array}\right)$ & 0.1588 & 32.61 & 32.38 & 2.7437 & 2.7626 & $\mathrm{a}=3.1900 \mathrm{c}=5.1890$ & $=3.1681 \mathrm{c}=5.1735$ & 54.42 \\
\hline & $\left(\begin{array}{lll}1 & 1 & 0\end{array}\right)$ & 0.1571 & 61.39 & 59.70 & 1.5090 & 1.5475 & $\mathrm{a}=3.0950 \mathrm{c}=5.0000$ & $=3.0180 \mathrm{c}=4.9283$ & 61.40 \\
\hline \multirow[t]{2}{*}{75} & $\left(\begin{array}{lll}1 & 0 & 0\end{array}\right)$ & 0.1639 & 32.61 & 32.38 & 2.7437 & 2.7626 & $\mathrm{a}=3.1900 \mathrm{c}=5.1890$ & $=3.1681 \mathrm{c}=5.1735$ & 52.73 \\
\hline & $\left(\begin{array}{lll}1 & 1 & 0\end{array}\right)$ & 0.1617 & 61.37 & 59.70 & 1.5094 & 1.5475 & $\mathrm{a}=3.0950 \mathrm{c}=5.0000$ & $=3.0188 \mathrm{c}=4.9297$ & 59.65 \\
\hline \multirow[t]{2}{*}{100} & $\left(\begin{array}{lll}1 & 0 & 0\end{array}\right)$ & 0.1646 & 32.61 & 32.38 & 2.7437 & 2.7626 & $\mathrm{a}=3.1900 \mathrm{c}=5.1890$ & $=3.1681 \mathrm{c}=5.1735$ & 52.50 \\
\hline & $\left(\begin{array}{lll}1 & 1 & 0\end{array}\right)$ & 0.1681 & 61.37 & 59.70 & 1.5094 & 1.5475 & $\mathrm{a}=3.0950 \mathrm{c}=5.0000$ & $=3.0188 \mathrm{c}=4.9297$ & 57.38 \\
\hline \multirow[t]{2}{*}{125} & $\left(\begin{array}{lll}1 & 0 & 0\end{array}\right)$ & 0.1722 & 32.61 & 32.38 & 2.7437 & 2.7626 & $\mathrm{a}=3.1900 \mathrm{c}=5.1890$ & $=3.1681 \mathrm{c}=5.1735$ & 50.19 \\
\hline & $\left(\begin{array}{lll}1 & 1 & 0\end{array}\right)$ & 0.1719 & 61.37 & 59.70 & 1.5094 & 1.5475 & $\mathrm{a}=3.0950 \mathrm{c}=5.0000$ & $=3.0188 \mathrm{c}=4.9297$ & 56.11 \\
\hline
\end{tabular}

*Standard values from ICSD codes: 01-076-0703 and 01-079-2499.

Table 3. Strain in GaN/p-Si thin films grown by RF magnetron sputtering at different RF powers.

\begin{tabular}{|c|c|c|c|c|c|}
\hline $\begin{array}{c}\text { RF } \\
\text { power [W] }\end{array}$ & (h k l) & $\begin{array}{c}\text { Out-of-plane } \\
\text { strain }\left(\varepsilon_{\mathrm{c}}\right) \\
\end{array}$ & $\begin{array}{c}\text { In-plane } \\
\text { strain }\left(\varepsilon_{\mathrm{a}}\right)\end{array}$ & $\begin{array}{c}\text { In-plane stress } \\
\left(\sigma_{\mathrm{a}}\right)[\mathrm{GPa}]\end{array}$ & $\begin{array}{c}\text { Type } \\
\text { of stress }\end{array}$ \\
\hline \multirow[t]{2}{*}{50} & $\left(\begin{array}{lll}1 & 0 & 0\end{array}\right)$ & -0.0022 & -0.0062 & 0.9996 & Compressive \\
\hline & $\left(\begin{array}{lll}1 & 1 & 0\end{array}\right)$ & -0.0495 & -0.0533 & 5.5958 & Compressive \\
\hline \multirow[t]{2}{*}{75} & $\left(\begin{array}{lll}1 & 0 & 0\end{array}\right)$ & -0.0022 & -0.0062 & 0.9996 & Compressive \\
\hline & $\left(\begin{array}{lll}1 & 1 & 0\end{array}\right)$ & -0.0492 & -0.0530 & 5.5664 & Compressive \\
\hline \multirow[t]{2}{*}{100} & $\left(\begin{array}{lll}1 & 0 & 0\end{array}\right)$ & -0.0022 & -0.0062 & 0.9996 & Compressive \\
\hline & $\left(\begin{array}{lll}1 & 1 & 0\end{array}\right)$ & -0.0492 & -0.0530 & 5.5664 & Compressive \\
\hline \multirow[t]{2}{*}{125} & $\left(\begin{array}{lll}1 & 0 & 0\end{array}\right)$ & -0.0022 & -0.0062 & 0.9996 & Compressive \\
\hline & $\left(\begin{array}{lll}1 & 1 & 0\end{array}\right)$ & -0.0492 & -0.0530 & 5.5664 & Compressive \\
\hline
\end{tabular}

in the literature studies [55]. Our average roughness of the $\mathrm{GaN}$ thin films has ranged from $0.59 \mathrm{~nm}$ to $1.05 \mathrm{~nm}$, indicating lower value than those from literature studies. The highest average roughness was found to be $1.05 \mathrm{~nm}$ for $75 \mathrm{~W}$ RF power growth condition, whereas the lowest average roughness was found to be $0.59 \mathrm{~nm}$ for $125 \mathrm{~W}$ RF power growth condition. From device application point of view, it is important to know when you want to select a rougher or smoother surface, which device you prefer and which features of this device are vital. It was found that increased interface roughness of $\mathrm{AlGaN} / \mathrm{GaN}$ heterostructure led to a decrease in mobility, indicating interface roughness role in tailoring electrical properties of the device [56]. However, it was shown that rougher surface contributed to improvement of light extraction for thin film LED thanks to increasing light extraction ability of the micro roughness surface. The roughness role in optical properties of the device was discussed in the literature [57]. By changing RF power, we obtained GaN thin films with better surface morphology. In the long run, thin films with better surface morphology could be obtained by optimizing the other growth parameters in addition to the RF power, thereby producing more efficient devices.

\subsection{Morphological analysis by SEM}

Before SEM measurements, GaN thin films were coated with $\sim 5 \mathrm{~nm}$ thick $\mathrm{Au}$ in vacuum. The reason was the elimination of excess electrons by preventing their accumulation on the film surface. Furthermore, it improved SEM imaging due to conduction of Au. The secondary electron method was used to analyze of the morphological and structural properties of $\mathrm{GaN}$ thin film surface. SEM images of thin films were taken at $\times 50000$ magnification. SEM images of GaN/p-Si films obtained at various RF powers are displayed in Fig. 4. It is seen 
Table 4. Morphological parameters of GaN/p-Si thin films for different RF powers.

\begin{tabular}{cccccc}
\hline $\begin{array}{c}\mathrm{RF} \\
\text { power [W] }\end{array}$ & $\begin{array}{c}\text { Average } \\
\text { roughness } \mathrm{R}_{\mathrm{a}}[\mathrm{nm}]\end{array}$ & $\begin{array}{c}\text { Maximum peak } \\
\text { height } \mathrm{R}_{\mathrm{p}}[\mathrm{nm}]\end{array}$ & $\begin{array}{c}\text { Root mean square } \\
\text { roughness RMS [nm] }\end{array}$ & $\begin{array}{c}\text { Average absolute Maximum valley } \\
\text { slope } \Delta \mathrm{a}\left[{ }^{\circ}\right]\end{array}$ & \begin{tabular}{c} 
depth $\mathrm{R}_{\mathrm{v}}[\mathrm{nm}]$ \\
\hline \hline
\end{tabular} \\
\hline 50 & 0.79 & 2.69 & 0.98 & 4.57 & 2.25 \\
75 & 1.05 & 4.60 & 1.35 & 6.37 & 3.10 \\
100 & 0.74 & 2.63 & 0.91 & 5.91 & 2.28 \\
125 & 0.59 & 2.77 & 0.74 & 4.46 & 1.87 \\
\hline
\end{tabular}

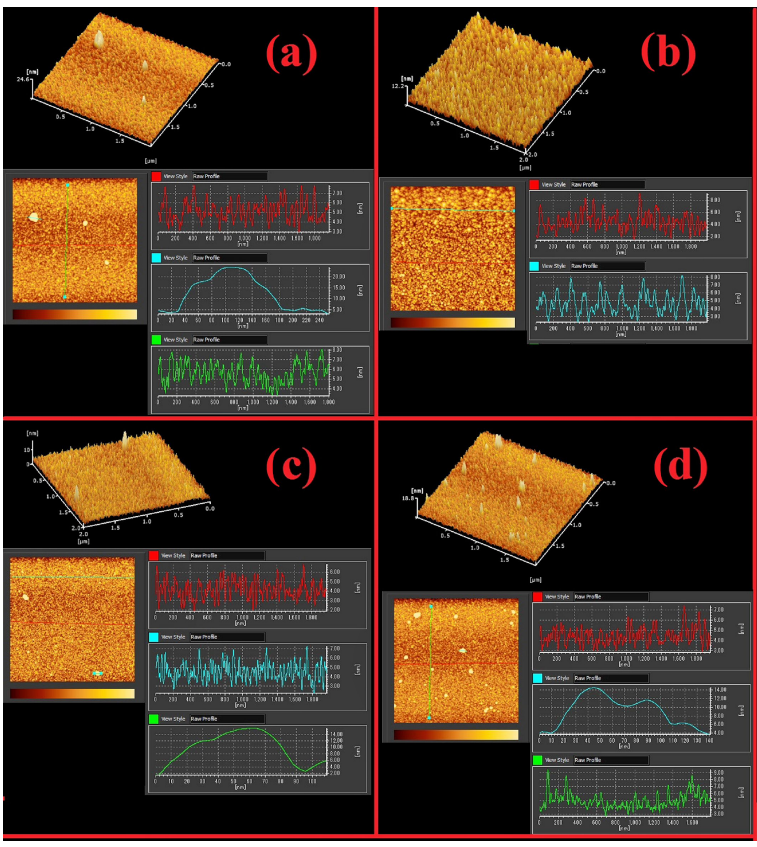

Fig. 2. AFM images of $\mathrm{GaN} / \mathrm{p}-\mathrm{Si}$ thin films obtained at (a) $50 \mathrm{~W}$ (b) $75 \mathrm{~W}$ (c) $100 \mathrm{~W}$ (d) $125 \mathrm{~W} \mathrm{RF}$ power.

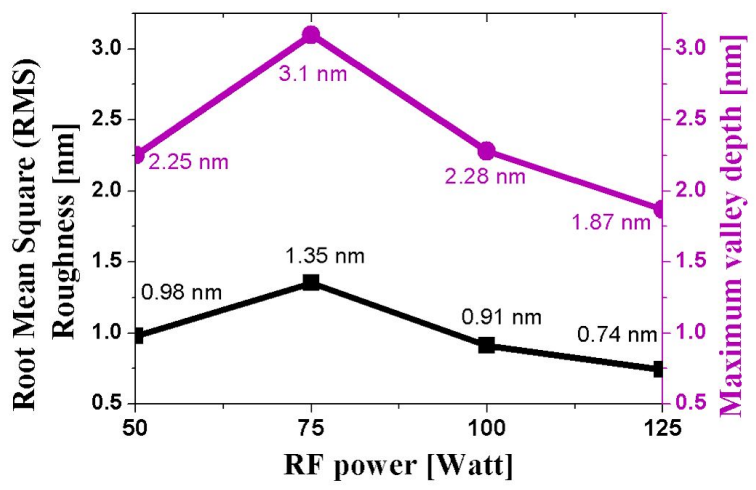

Fig. 3. The plot of root mean square (RMS) roughness and maximum valley depth versus RF power value.

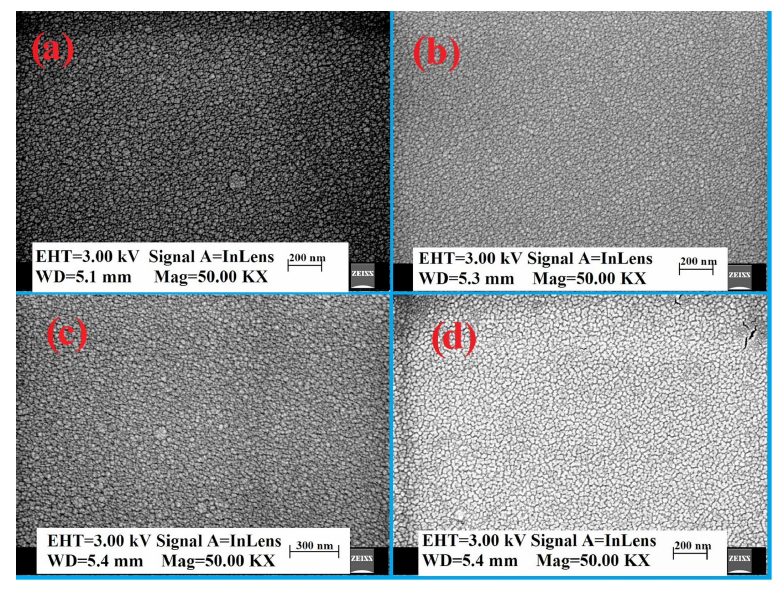

Fig. 4. SEM images of GaN/p-Si thin films obtained at (a) $50 \mathrm{~W}$, (b) $75 \mathrm{~W}$, (c) $100 \mathrm{~W}$, (d) $125 \mathrm{~W} \mathrm{RF}$ power.

that some dislocations on the surface of the $\mathrm{GaN}$ thin film have appeared under $125 \mathrm{~W}$ growth condition. The dislocations may increase fragility of the GaN thin film in those regions. Dislocations could contribute to strain relaxation of InGaN/GaN quantum dots which is important in device applications [58]. It has been reported that threading dislocations in $\mathrm{p}-\mathrm{GaN}$ capping layer led to deterioration of performance of InGaN/GaN solar cell devices [59]. Detailed analysis of dislocations could be made by cathodoluminescence mapping (CL) and photoluminescence imaging techniques, going beyond our study. It has been observed that SEM images confirm that the grain sizes of the films have varied with RF power. Some aggregations on the surface of thin film are seen for $50 \mathrm{~W}$ and $100 \mathrm{~W}$ RF power growth conditions. We think that these agglomerations may be attributed to Van der Waals forces between GaN molecules due to polarization which has also been postulated in [60]. 
Aggregation growth may affect properties of the material. It was found that indium aggregation in InGaN/GaN multiple quantum wells resulted in InGaN mounds, forming localized states for trapping carriers. Therefore, increased indium aggregation could improve luminescence efficiency in reported study [61]. It was seen that the morphological structure of the thin film is deteriorated by increasing the RF power, which is in agreement with the XRD results. It has been concluded from the SEM analysis that surface morphology of our material can be changed by controlling radio frequency power.

\subsection{Optical analysis}

\subsubsection{Determination of optical band gap en- ergy by UV-Vis-NIR}

Optical band gap energy $E_{g}$ is defined as energy difference between the lowest point of conduction band and the highest point of valence band. Several important photonic and optoelectronic devices are based on controlling the optical band gap $E_{g}$. The optical band gap can be calculated from the wellknown Tauc formula [62, 63]:

$$
(\alpha h v)^{n}=C\left(h v-E_{g}\right)
$$

where $\mathrm{n}$ shows band gap type, $\mathrm{C}$ is a constant, $h v$ is the photon energy, and $E_{g}$ is the optical band gap energy of GaN thin film. For $\mathrm{n}=1 / 2$, $\mathrm{E}_{\mathrm{g}}$ displays direct-allowed band gap. Absorbance versus wavelength $(\mathrm{nm})$ graph was obtained from UV-Vis-NIR spectrophotometry. Fig. 5 presents $(\alpha \mathrm{h} v)^{2}$ vs. photon energy E plot of GaN/p-Si thin films obtained at various RF powers. Extrapolating the $(\alpha \mathrm{h} v)^{2}$ vs. E plot to the intersection with energy axis the value of optical band gap of $\mathrm{GaN}$ thin films can be obtained. In this way, optical band gap energy $E_{g}$ values of $\mathrm{GaN}$ thin films obtained at different RF powers were found to be $3.5283 \mathrm{eV}$, $3.5359 \mathrm{eV}, 3.5270 \mathrm{eV}, 3.5258 \mathrm{eV}$ for $50 \mathrm{~W}, 75 \mathrm{~W}$, $100 \mathrm{~W}$, and $125 \mathrm{~W}$, respectively. They are given in Table 5. It is seen that increasing RF power from $50 \mathrm{~W}$ to $75 \mathrm{~W}$ has led to an increment of optical band gap of thin film whereas increasing RF power from $75 \mathrm{~W}$ to $100 \mathrm{~W}$ has led to decreasing optical band gap energy of $\mathrm{GaN}$ thin film. Increasing $\mathrm{RF}$
Table 5. Optical band gap energy of GaN/p-Si thin films.

\begin{tabular}{cc}
\hline Applied RF power [W] Optical band gap energy [eV] \\
\hline \hline 50 & 3.5283 \\
75 & 3.5359 \\
100 & 3.5270 \\
125 & 3.5258 \\
\hline
\end{tabular}

power from $100 \mathrm{~W}$ to $125 \mathrm{~W}$ has caused slight decrease in optical band gap energy of GaN thin film. It is observed that the change in optical band gap value of GaN thin films caused by RF power shows non-linear behavior. It can be attributed to the presence of defects leading to a change in optical band gap of $\mathrm{GaN}$ thin film. The literature study gives very important information about defects in GaN material [64]. Though defect control in thin film is not very easy, it is possible to reduce their number by applying annealing process to the films and by improving the vacuum during the growth process. Our optical band gap energy values are larger than those reported in the previous studies [65-67]. To sum up, it was found that the varying RF power changed the film optical band gap value in a nonlinear manner (the importance of controlling the optical band gap for optoelectronic device has been discussed in the literature [68]).

\subsubsection{Determination of optical phonon modes by micro Raman}

Crystal structure of hexagonal $\mathrm{GaN}$, belonging to $\mathrm{C}_{6 \mathrm{v}}^{4}$ space group, is in a stable state. According to group theory, hexagonal $\mathrm{GaN}$ has six Raman active modes, i.e. $1 \mathrm{E}_{1}(\mathrm{TO})+1 \mathrm{E}_{1}(\mathrm{LO})+2 \mathrm{E}_{2}+1 \mathrm{~A}_{1}(\mathrm{TO})+$ $1 \mathrm{~A}_{1}$ (LO). Raman spectra of GaN/p-Si thin films obtained at various RF powers are shown in Fig. 6. The peaks at $572.59 \mathrm{~cm}^{-1}, 572.59 \mathrm{~cm}^{-1}$, $570.95 \mathrm{~cm}^{-1}, 572.04 \mathrm{~cm}^{-1}$ have been detected for $50 \mathrm{~W}, 75 \mathrm{~W}, 100 \mathrm{~W}, 125 \mathrm{~W}$ radio frequency power. It corresponds to the vibration of $\mathrm{E}_{2}$ (high) and has been supported by the previous study [69]. From the Raman measurements, it is seen that the highest Raman intensity corresponds to $50 \mathrm{~W}$ RF power and the lowest Raman intensity corresponds to $100 \mathrm{~W}$ RF power, as is clearly seen in Fig. 6. 
This higher Raman intensity could be attributed to surface states and plasmon phonon coupling effects [70, 71]. Stress free Raman shift of $E_{2}$ (high) optical phonon vibration of $\mathrm{GaN}$ thin film was reported to be $567.2 \mathrm{~cm}^{-1}[72,73]$. If the Raman shift of $\mathrm{GaN}$ thin film of $\mathrm{E}_{2}$ (high) optical phonon vibration is higher than the stress free value (higher wave number), it is called blue shift. In this case, thin film shows a compressive stress. On the contrary, if the Raman shift of the GaN thin film of $E_{2}$ (high) optical phonon vibration is lower than stress free value (it is in the lower wave number), it is called red shift. This implies that GaN thin film shows a tensile stress. Raman results for our thin films have shifted to the blue zone, as shown in Fig. 6. The Raman results suggest that our films have compressive stress. The in-plane stress in the GaN thin film obtained from the XRD results has been defined as compressive stress. The results obtained by Raman and XRD are consistent. Characterization and analysis of the stress in GaN thin films is important for device application because tensile stress causes cracking of the device and limitation of the sheet usable thickness [74]. Compressive stress causes buckling of the layer and its separation in the device [75]. This leads to short circuit problems in the device.

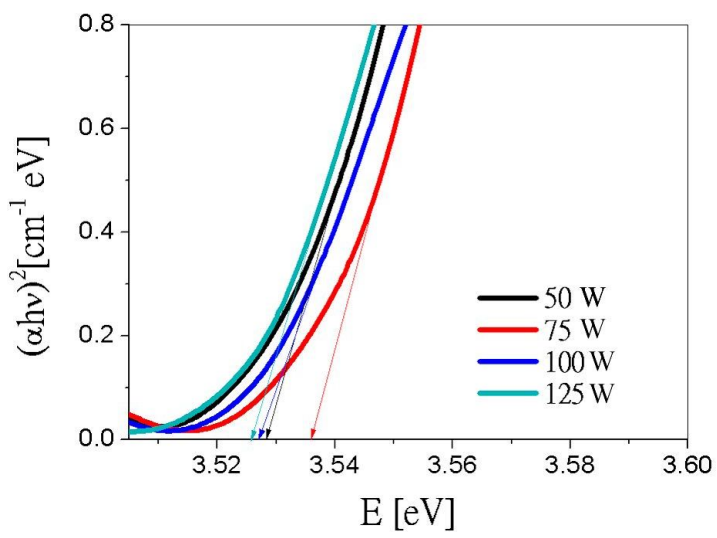

Fig. 5. $(\alpha \mathrm{h} v)^{2}$ plot versus photon energy E of GaN/p-Si films obtained at various RF powers.

\section{Conclusions}

Hexagonal GaN thin films with polycrystalline structure were successfully produced on $\mathrm{p}-\mathrm{Si}$

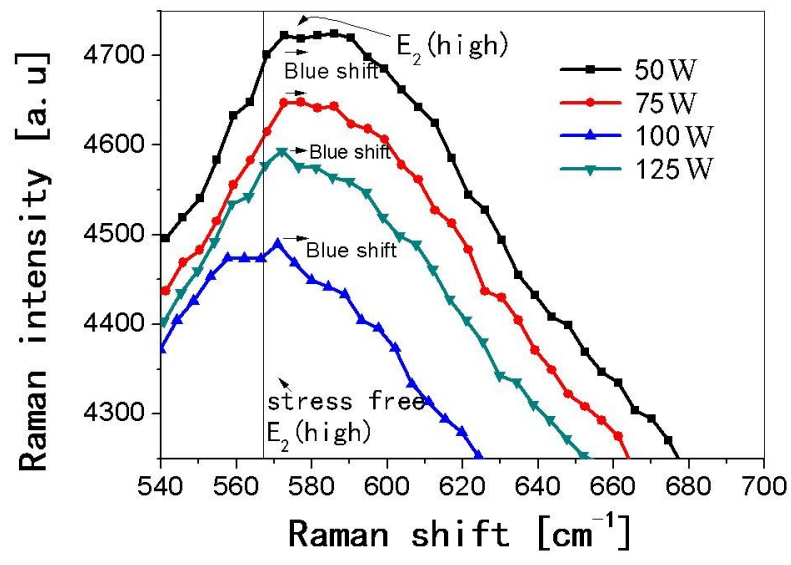

Fig. 6. Raman spectra of $\mathrm{GaN} / \mathrm{p}-\mathrm{Si}$ thin films obtained at various RF powers.

substrates by RF magnetron sputtering. Increasing $\mathrm{RF}$ power led to deterioration in crystal structure of GaN thin films because of increased decomposition of GaN, resulting in an increment in vacancies of gallium and nitrogen. Structures of GaN/pSi thin film with the best and the worst crystallinity were obtained for $50 \mathrm{~W}$ and $125 \mathrm{~W}$ RF power growth condition, proving that optimum RF power value for growing our thin film was $50 \mathrm{~W}$. It was found that the varying RF power changed the thin film optical band gap value in a non-linear manner. This variation was caused by defects during the growth process. Some aggregations on the surface of the films resulting from van der Waals forces between the particles were observed for $50 \mathrm{~W}$ and $100 \mathrm{~W}$ RF power whereas dislocations were created at $125 \mathrm{~W}$ RF power. Characteristic $\mathrm{E}_{2}$ (high) optical phonon mode of hexagonal GaN was noticed. Raman analysis revealed that the films have compressive stress. In-plane stress in the GaN thin films, caused by the differences in lattice parameters and thermal coefficients, obtained from the XRD studies was classified as compressive stress. When the results of Raman and XRD studies were compared, it was found that they were consistent. In this work, we have proved that altering RF power makes possible to control the morphological, optical and structural properties of GaN thin films. Thus, by appropriate choice of this parameter we are able to grow better quality GaN thin films for optoelectronic device applications. 


\section{Acknowledgements}

This work was supported by the Muş Alparslan University Scientific Research Coordination Unit. The Project Number: BAP-18FEF-4901-03.

\section{References}

[1] Neumayer D.A., Ekerdt J.G., Chemistry of Materials, 8 (1996), 9.

[2] Strite S., Morkoc H., J. Vac. Sci. Technol. B, B10 (1992), 1237.

[3] Hu X.-L., Wen R.-L., Qi Z.-Y., WANG H., Materials Science in Semiconductor Processing, 79 (2018), 61.

[4] Mantarci A., Kundakçi M., Bulletin of Materials Science, 42 (2019), 196.

[5] Brendel M., Pertzsch E., Abrosimova V., TRENKLER T., Weyers M., in: M. KNEISSL, J. RASS (Eds.), III-Nitride Ultraviolet Emitters: Technology and Applications, Springer International Publishing, Cham, 2016, p. 219.

[6] King S.W., Davis R.F., Nemanich R.J., Journal of Vacuum Science \& Technology A: Vacuum, Surfaces, and Films, 32 (2014), 061504.

[7] Mantarci A., Emerg. Mater. Res., 8 (2019), 1.

[8] Ajay A., Kotsar Y., Monroy E., in: J. Huang, H.-C. KUO, S.-C. SHEN (Eds.) Nitride Semiconductor Light-Emitting Diodes (LEDs) (Second Edition), Woodhead Publishing, 2018, pp. 587.

[9] Chatterjee U., Park J.-H., UM D.-Y., LeE C.-R., Renewable and Sustainable Energy Reviews, 79 (2017), 1002.

[10] PAmpili P., Parbrook P.J., Materials Science in Semiconductor Processing, 62 (2017), 180.

[11] Mantarci A., KundaKçi M., Opt. Quant. Electron., 51 (2019), 81.

[12] He X.G., ZhaO D.G., JiAng D.S., ZhU J.J., Chen P., LIU Z.S., LE L.C., YANG J., LI X.J., LIU J.P., ZHANG L.Q., YANG H., Journal of Alloys and Compounds, 662 (2016), 16.

[13] Saito W., Suwa T., Uchihara T., Naka T., KoBAYASHI T., Microelectronics Reliability, 55 (2015), 1682.

[14] Moon W.H., KIM H.J., Choi C.H., Scripta Materialia, 56 (2007), 345.

[15] LeE J.-M., Min B.-G., Ju C.-W., Ahn H.-K., LiM J.-W., Current Applied Physics, 17 (2017), 157.

[16] Qian H., LeE K.B., Vajargah S.H., Novikov S.V., GUINEY I., ZAIDI Z.H., JiANG S., WALlis D.J., FoXon C.T., HuMphreys C.J., Houston P.A., Journal of Crystal Growth, 459 (2017), 185.

[17] Miyoshi M., Tsutsumi T., Kabata T., Mori T., EgAWA T., Solid-State Electronics, 129 (2017), 29.

[18] Sheu J.-K., Chen P.-C., Shin C.-L., LeE M.-L., Liao P.-H., LaI W.-C., Solar Energy Materials and Solar Cells, 157 (2016), 727.

[19] Xing Z., Wang R.X., FAn Y.M., Wang J.F., Zhang B.S., XU K., Materials Science in Semiconductor Processing, 57 (2017), 132.
[20] LiU Z., Chong W.C., Wong K.M., Lau K.M., Microelectronic Engineering, 148 (2015), 98.

[21] Lin J.-H., HuAng S.-J., Su Y.-K., HuAnG K.-W., Applied Surface Science, 354 (2015), 168.

[22] Mantarci A., GÜndüZ B., Optical and Quantum Electronics, 48 (2016), 547.

[23] Martinez-Guerrero E., Adelmann C., Chabuel F., Simon J., Pelekanos N.T., Mula G., Daudin B., Feuillet G., Mariette H., Applied Physics Letters, 77 (2000), 809.

[24] Ambacher O., Majewski J., Miskys C., Link A., HermanN M., EICKhOFF M., STUTZMANN M., BERnARdini F., Fiorentini V., TIlaK V., SCHAFF B., EASTMAN L.F., Journal of Physics: Condensed Matter, 14 (2002), 3399.

[25] Wang M., Bian J., Sun H., LiU W., Zhang Y., Luo Y., Applied Surface Science, 389 (2016), 199.

[26] Gu S., Chagarov E.A., Min J., Madisetti S., NoVAK S., OKTYABRSKy S., KerR A.J., KaufmanOsborn T., Kummel A.C., Asbeck P.M., Applied Surface Science, 317 (2014), 1022.

[27] Mantarci A., Kundakçi M., AIP Conference Proceedings, 1833 (2017), 020119.

[28] Braniste T., Ciers J., Monaico E., Martin D., Carlin J.F., Ursaki V.V., Sergentu V.V., Tiginyanu I.M., GRANDJEAN N., Superlattices and Microstructures, 102 (2017), 221.

[29] Mutlu K., Asim M., Erman E., Materials Research Express, 4 (2017), 016410.

[30] ERdoĞAn E., Kundakçi M., Mantarci A., in: Journal of Physics: Conference Series, IOP Publishing, 2016, pp. 012019.

[31] Fong C.Y., Ng S.S., Yam F.K., Abu Hassan H., HASSAN Z., Vacuum, 119 (2015), 119.

[32] Kawwam M., Lebbou K., Applied Surface Science, 292 (2014), 906.

[33] Yin M.L., Zou C.W., Li M., LiU C.S., GuO L.P., FU D.J., Nuclear Instruments and Methods in Physics Research Section B: Beam Interactions with Materials and Atoms, 262 (2007), 189.

[34] Shinoda H., Mutsukura N., Vacuum, 125 (2016), 133.

[35] Li L., Huang J., Yang W., Tang K., Ren B., Xu H., Wang L., Surface and Coatings Technology, 307 (2016), 1024.

[36] Abud S.H., Selman A.M., Hassan Z., Superlattices and Microstructures, 97 (2016), 586.

[37] Yudate S., FujiI T., Shirakata S., Thin Solid Films, 517 (2008), 1453.

[38] LiUan L., Yonggang X., QIngPeng W., Ryosuke N., Ying J., Jin-PING A., Semiconductor Science and Technology, 30 (2015), 015019.

[39] Shinoda H., Mutsukura N., Thin Solid Films, 516 (2008), 2837.

[40] Kuo D.-H., Tuan T.T.A., Li C.-C., Yen W.-C., Materials Science and Engineering: B, 193 (2015), 13.

[41] Biswas A., Bhattacharyya D., Sahoo N.K., YaDAV B.S., MAJOR S.S., SRINIVASA R.S., Journal of Applied Physics, 103 (2008), 083541. 
[42] Selman A.M., Hassan Z., Husham M., Measurement, 56 (2014), 155.

[43] Schulz H., Thiemann K.H., Solid State Communications, 23 (1977), 815.

[44] Yeh C.-Y., Lu Z.W., Froyen S., Zunger A., Physical Review B, 46 (1992), 10086.

[45] OraK I., Kocyigit A., TURUT A., Journal of Alloys and Compounds, 691 (2017), 873.

[46] Patterson A.L., Physical Review, 56 (1939), 978.

[47] Hughes W.C., JR. W.H.R., Johnson M.A.L., FuJitA S., JR. J.W.C., SChetzina J.F., REN J., EDMOND J.A., Journal of Vacuum Science \& Technology B: Microelectronics and Nanometer Structures Processing, Measurement, and Phenomena, 13 (1995), 1571.

[48] Proceedings of the Royal Society of London. Series A, 88 (1913), 428.

[49] Aggarwal N., Krishna S.T.C., Goswami L., Mishra M., Gupta G., Maurya K.K., Singh S., Dilawar N., Kaur M., Crystal Growth \& Design, 15 (2015), 2144.

[50] LiU L., EdGaR J.H., Materials Science and Engineering: R: Reports, 37 (2002), 61.

[51] Kisielowski C., KRÜger J., Ruvimov S., Suski T., Ager J.W., Jones E., LilientalWeber Z., RUbin M., Weber E.R., BREMSER M.D., DaVis R.F., Physical Review B, 54 (1996), 17745.

[52] Kozawa T., Kachi T., Kano H., Nagase H., Koide N., Manabe K., Journal of Applied Physics, 77 (1995), 4389.

[53] Van De Walle C.G., Physical Review B, 68 (2003), 165209.

[54] Kaufmann N.A., Lahourcade L., Hourahine B., Martin D., Grandjean N., Journal of Crystal Growth, 433 (2016), 36.

[55] KIM H.W., KIM N.H., Applied Surface Science, 236 (2004), 192.

[56] Demir M., Yarar Z., Ozdemir M., Solid State Communications, 158 (2013), 29.

[57] Li J.-S., TANG Y., Li Z.-T., Ding X.-R., Li Z., Applied Surface Science, 410 (2017), 60.

[58] Yang D., Wang L., HaO Z.-B., Luo Y., Sun C., HAN Y., XIONG B., WANG J., LI H., Superlattices and Microstructures, 99 (2016), 221.

[59] Zhang Y., Kappers M.J., Zhu D., Oehler F., GaO F., Humphreys C.J., Solar Energy Materials and Solar Cells, 117 (2013), 279.
[60] Kudrawiec R., NyK M., SyPereK M., PoDHOROdecki A., Misiewicz J., Strek W., Applied Physics Letters, 88 (2006), 181916.

[61] You Y.-S., Feng S.-W., Wang H.-C., Song J., HAN J., Journal of Luminescence, 182 (2017), 196.

[62] TAUC J., Menth A., Journal of Non-Crystalline Solids, 8 (1972), 569.

[63] STEnzel O., The physics of thin film optical spectra, Springer, 2005.

[64] Reshchikov M.A., Usikov A., Helava H., Makarov Y., Prozheeva V., MakKonen I., TuOmisto F., Leach J.H., Udwary K., Scientific Reports, 7 (2017), 9297.

[65] SAID A., DeBBichi M., SAID M., Optik-International Journal for Light and Electron Optics, 127 (2016), 9212.

[66] Gueddim A., Eloud T., Messikine N., Bouariss A N., Superlattices and Microstructures, 77 (2015), 124.

[67] Liao J.-H., Huang H.-W., Cheng L.-C., LiU H.-H., ChYi J.-I., CAI D.-P., CHEN C.-C., LAI K.-Y., Solar Energy Materials and Solar Cells, 132 (2015), 544.

[68] Zhang H., Zhang D., WANG W., Journal of Luminescence, 192 (2017), 470.

[69] Hiroshi H., Journal of Physics: Condensed Matter, 14 (2002), R967.

[70] Sekine T., Komatsu Y., Iwaya R., Kuroe H., KIKUCHI A., KISHINO K., Journal of the Physical Society of Japan, 86 (2017), 074602.

[71] DYSON A., Journal of physics. Condensed matter: an Institute of Physics journal, 21 (2009), 174204.

[72] Nootz G., Schulte A., Chernyak L., OsinSKY A., JASinski J., Benamara M., LilientalWeber Z., Applied Physics Letters, 80 (2002), 1355.

[73] Park B.-G., Saravana Kumar R., Moon M.-L., Kim M.-D., Kang T.-W., YAnG W.-C., Kim S.-G., Journal of Crystal Growth, 425 (2015), 149.

[74] Mizushima I., TANg P.T., Hansen H.N., Somers M.A.J., Electrochimica Acta, 51 (2006), 6128.

[75] Moon M.W., Chung J.W., LeE K.R., OH K.H., Wang R., Evans A.G., Acta Materialia, 50 (2002), 1219. 